\title{
REFLEXÕES SOBRE A DOCÊNCIA: NARRATIVAS DE PROFESSORES DE MATEMÁTICA EM FORMAÇÃO
}

\author{
THINKING ABOUT TEACHING: MATHEMATICS PRE-SERVICE TEACHER'S NARRATIVES
}

\author{
Julia Schaetzle Wrobel
}

Universidade Federal do Espírito Santo

E-mail: juliasw@gmail.com

\section{Sandra Aparecida Fraga da SIlva \\ Instituto Federal do Espírito Santo \\ E-mail: sandrafraga7@gmail.com}

\section{Resumo}

Refletir sobre vivências das próprias experiências e do meio sociocultural onde está inserido mostra como licenciandos constroem seus saberes, como apontam Fiorentini, Mizukami e Pimenta. Nesse sentido, realizamos uma pesquisa qualitativa exploratória com licenciandos de matemática de duas instituições federais do Espírito Santo com o objetivo de analisar situações vividas por professores em formação, enquanto ainda eram alunos, para identificar aspectos da formação da identidade docente e saberes docentes. Tomando como base Fiorentini, notamos que os sujeitos privilegiam o saber subjetivo, com destaque para relacionamento professor-aluno. Concluímos que provocar essas reflexões contribui para que os licenciandos comecem a se perceber professores e que reconheçam que esta constituição docente é fruto de diferentes experiências vividas antes da universidade.

Palavras-chave: formação de professores. saberes docentes. estágio supervisionado. experiências e matemática.

\begin{abstract}
Thinking about own experiences and socio-cultural environment in which it operates shows how licensees build their knowledge, according to Fiorentini, Mizukami and, Pimenta. In this way, we performed an exploratory qualitative research with mathematics undergraduates of two federal institutions of Espírito Santo - Brazil. Our Goal was to analyze situations they had experienced while they were still students to identify aspects of the formation of teacher identity and teaching knowledge. Fiorentini taking as base, we noted that the students emphasize subjective knowledge, especially teacher-student relationship. We conclude emphasizing that these reflections contribute to the undergraduates begin to realize as teachers and to recognize that this teaching establishment is the result of different experiences before college.
\end{abstract}

Palavras-chave: teacher training. teaching knowledge. supervised training. experiences and mathematics. 


\section{INTRODUÇÃO}

Apresentamos neste trabalho um recorte de uma pesquisa realizada em duas instituições públicas federais de ensino superior que possuem licenciatura em matemática em Vitória/ES. Esta pesquisa mais ampla versa sobre identidade docente e saberes docentes, com o objetivo de analisar situações vividas por professores em formação, enquanto ainda eram alunos, com a intenção de identificar aspectos da formação da identidade docente e saberes docentes apontados por esses sujeitos.

O processo de ser e tornar-se professor é fruto de diferentes situações estabelecidas enquanto alunos e enquanto professores e de relações que cada um vivencia por meio das próprias experiências e do meio sociocultural onde está inserido (FIORENTINI, 2005; MIZUKAMI, 2006; PIMENTA, 1997). A prática do professor é construída a partir de muitas referências, "sua trajetória escolar e acadêmica, sua convivência com o ambiente de trabalho, sua inserção cultural no tempo e no espaço" (CUNHA, 1997, p.189). Começa antes mesmo da formação inicial da graduação, enquanto ainda se é estudante e continua durante e após o curso de licenciatura (LLINARES; KRAINER, 2006; MIZUKAMI, 2006). Compactuando desta ideia Tardif (2000) chama a atenção para o fato de que os futuros professores frequentam a salas de aula por mais de 15 anos antes de começar a trabalhar nelas e essa vivência certamente têm influência sobre sua concepção de professor.

O saber dos professores não é um conjunto de conteúdos cognitivos definidos de uma vez por todas, mas um processo em construção ao longo de uma carreira profissional na qual o professor aprende progressivamente a dominar seu ambiente de trabalho, ao mesmo tempo em que se tornam parte integrante de sua ciência prática (TARDIF, 2002, p.14).

Um dos primeiros autores a organizar esses conhecimentos próprios para o ensino foi Shulman (1986), realizando uma categorização dos conhecimentos necessários à ação docente. Num primeiro momento, os conhecimentos foram agrupados em três blocos: da disciplina (subject knowledge matter), pedagógico ou didático do conteúdo (pedagogical 
knowledge matter) e curricular (curricular knowledge). Realizando essa classificação deixou evidente a natureza complexa dos conhecimentos docentes que são utilizados no processo de ensino e aprendizagem. Além disso, mostrou a necessidade de integração do conhecimento do conteúdo a ser ensinado, no nosso caso o conhecimento matemático, com o conhecimento sobre como ensinar tal conteúdo (SHULMAN, 1986).

Analisando o trabalho do professor, Shulman identificou que ele está relacionado a diferentes ações para além da sua disciplina e ao ensino do conteúdo. Existem muitos fatores que interferem no processo de ensino e aprendizagem: os alunos, o contexto escolar no qual está inserido, o conteúdo e etc. Nesse sentido, Shulman (2005) amplia e modifica a sua classificação, trazendo os blocos conhecimentos do conteúdo, conhecimento pedagógico geral, do currículo, pedagógico do conteúdo, dos alunos e suas características, do contexto educativo e o conhecimento relacionado aos objetivos, finalidades e valores educacionais.

Outros pesquisadores reorganizaram os saberes e/ou conhecimentos ${ }^{1}$ docentes a partir de estudos sobre a categorização realizada por Shulman. Fiorentini (2005) reorganizou as ideias de Shulman defendendo a existência de três dimensões de saberes docentes: "dimensão do saber acadêmico (veiculado e enfatizado nas disciplinas da licenciatura), dimensão subjetiva (saber ser professor-educador) e dimensão da prática (saber fazer)" (FIORENTINI, 2005, p.110).

Tardif (2002) também identificou e definiu os diferentes saberes presentes na prática docente. Assim como Shulman e Fiorentini, também para ele o saber docente é plural, provenientes de várias fontes. Tardif $(2002$, p. 33) define o saber docente como constituído de "saberes disciplinares, curriculares, profissionais (incluindo os das ciências da educação e da pedagogia), e experienciais".

1 Alguns autores realizam diferenciação entre saberes e conhecimentos, neste artigo não abordaremos esta questão, consideraremos como sinônimos, apesar de entender que outros autores fazem essa diferenciação. 
Em comum, todas essas concepções sobre saber/conhecimento docente trazem uma dimensão do saber que é o conhecimento técnico da matéria, outra dimensão que é o saber ensinar a matéria, suas particularidades, proposições e relações entre os diferentes conteúdos, e uma terceira dimensão que é subjetiva, que envolve as relações estabelecidas entre os agentes em sala de aula, concepções de professores e alunos sobre a Matemática, dentre outras, que está igualmente presente no saber docente (FIORENTINI, 2005).

O processo de formação docente ocorre dentro e fora do ambiente acadêmico. Ele se inicia com os futuros professores na condição de alunos da educação básica e continua nos cursos de graduação e, posteriormente, em suas experiências da docência. Todas essas instâncias propiciam uma construção própria do que é ser professor e dos saberes docentes necessários à sua atuação. Nóvoa e Finger (1988) tratam da necessidade de que a formação docente ocorra de modo a promover a reflexividade crítica, em uma perspectiva em que "[...] a formação é inevitavelmente um trabalho de reflexão sobre os percursos de vida" (NÓVOA; FINGER, 1988, p.116). Na mesma linha, Nacarato e Paiva (2006) destacam que

Saber por que se ensina, para que se ensina, para quem e como se ensina é essencial ao fazer em sala de aula. O professor precisa estar em constante formação e processo de reflexão sobre seus objetivos e sobre a consequência de seu ensino durante a sua formação, na qual ele é o principal protagonista, assumindo a responsabilidade por seu próprio desenvolvimento profissional. [...] a partir desses conhecimentos e crenças, é que o professor interpreta, compreende e conduz sua prática docente em relação à Matemática. (NACARATO; PAIVA, 2006, p. 92)

Nesse contexto de construção e mobilização de saberes docentes, a memória ocupa lugar de destaque no processo formativo de professores.

Ao tentar resgatar a memória que os alunos ou professores têm sobre sua trajetória de formação, estimula-se a reflexão individual e coletiva 
buscando-se identificar as influências deixadas pelas vivências marcantes do passado na prática ou na forma de conceber o ensino no momento presente. (ZIBETTI, 2000, p. 23)

Nos cursos de formação inicial ou continuada faz-se necessário esse regate à memória, seja para compreender algumas crenças e concepções de futuro professores ou de professores já formados.

Quando hoje, tomando distância de momentos por mim vividos ontem, os rememoro, deve ser, tanto quanto possível, em descrevendo a trama, fiel ao que ocorreu, mas, de outro lado, fiel ao momento em que reconheço e descrevo, o momento antes vivido. Os "olhos" com que "revejo" já não são os "olhos" com que "vi". Ninguém fala do que passou a não ser na e da perspectiva do que passa. O que não me parece válido é pretender que o que passou de certa maneira devesse ter passado como possivelmente, nas condições diferentes de hoje, passaria. Afinal o passado se compreende, não se muda. (FREIRE, 2003, p. 19)

Essas memórias precisam ser acompanhadas de reflexões críticas sobre o processo formativo. Pimenta (2002) traz à tona o pensamento e a reflexão próprios do ser humano e evidencia a contribuição desse processo reflexivo no exercício do professor e mais precisamente a formação inicial. Destacamos que esse pensamento e reflexão são próprios, porém, ocorrem em diferentes níveis. Refletir é um ato humano e acontecem de maneira intuitiva, sem um processo intencional e crítico sobre como se faz e o porquê se faz. Defendemos uma reflexão crítica que seja intencional investigando aspectos do processo de ensino e aprendizagem de matemática tanto num nível pessoal como coletivo. Assim o processo formativo da docência acontecerá de maneira satisfatória.

No nosso caso resgatamos memórias de futuros professores de matemática a partir de 
narrativas. O estudo das narrativas é um estudo da forma como os seres humanos experimentam o mundo, construindo e reconstruindo suas histórias pessoais e sociais (CONNELLY; CLANDININ, 1995, p.11-12). Além disso,

O recurso das narrativas na formação inicial ou continuada de professores que ensinam matemática permite a explicitação e a reflexão sobre o que são os chamados episódios marcantes. São situações que envolvem carga emotiva intensa, trazem à memória emoções positivas ou negativas para quem as vivenciou e representam, algumas vezes, momentos decisivos para mudanças, transformações etc. (PASSOS, OLIVEIRA, GAMA, 2013, p. 334)

Acreditamos que as narrativas dos professores em formação estão carregadas destes episódios marcantes. Ademais, Cunha (1997) defende que o trabalho com as narrativas é profundamente formativo, uma vez que as pessoas reconstrói a história vivida atribuindo-lhe novos significados. Ao narrar sua história, o sujeito organiza suas ideias, reconstruindo reflexivamente suas experiências. Essa autoanálise é responsável pela compreensão de sua própria prática. "A narrativa é a representação que deles faz o sujeito e, dessa forma, pode ser transformadora da própria realidade" (CUNHA, 1997, p.187).

Nesse sentido, apresentamos a análise de situações marcantes da educação básica, vividas e relatadas por professores de formação enquanto alunos a partir da nossa pesquisa. 


\section{METODOLOGIA E AMOSTRA DE PESQUISA}

O presente trabalho traz uma pesquisa qualitativa exploratória a partir de narrativas autobiográficas. As narrativas autobiográficas são um método por meio do qual os sujeitos participantes podem refletir sobre seu próprio processo de formação e tomar consciência das estratégias e espaços que, ao longo de sua vida, participaram de sua formação (NÓVOA; FINGER (1988); PONTE (1998)). Josso (1988) argumenta que o interesse da construção das narrativas de vida reside justamente em seu caráter subjetivo.

Esta subjetividade em ação realiza em seus próprios movimentos um exercício de objetivação, por efetuar a passagem da atividade mental interior para a transmissão pela linguagem, constituindo um processo de elaboração de sentido em que o sujeito confronta-se consigo mesmo e compreende o que foi estruturante e mobilizador em sua formação. (BASTIDES, 2012, p.26)

A coleta de dados deu-se em 2015 e nossa amostra foi composta por 21 alunos de Licenciatura em Matemática de duas instituições públicas federais de Ensino, sendo 11 alunos da Universidade Federal do Espírito Santo - Campus Vitória (UFES) e 10 alunos Instituto Federal do Espírito Santo - Campus Vitória (IFES). Essas são as duas únicas instituições federais localizadas na Grande Vitória e possuem curso de licenciatura com modelos diferentes.

O Curso da UFES foi o primeiro curso de licenciatura do Estado, reconhecido em 1970. Atualmente, os alunos ingressam no vestibular de Matemática e cursam um núcleo básico comum. A partir do 5ำ período optam por Licenciatura ou Bacharelado. Só então os licenciandos têm contato com disciplinas de formação pedagógica. Os alunos pesquisados na UFES tinham acabado de decidir-se pela Licenciatura, estavam começando o 5으 período.

A Licenciatura em Matemática no IFES é um curso relativamente novo, reconhecido em 2007 e apresenta uma estrutura bem diferente, onde ao longo dos quatro anos de formação os 
alunos têm disciplinas de conteúdos específicos de Matemática e pedagógicos.

No momento da coleta de dados, todos os licenciandos cursavam estágio supervisionado, que é o primeiro contato do futuro professor com a prática docente.

Pedimos aos professores em formação que escrevessem sobre um episódio marcante vivido em sala de aula enquanto eles ainda eram alunos (Figura 1). No IFES, foi solicitado que essa experiência fosse específica da educação básica, já na UFES não foi feita nenhuma indicação, portanto os sujeitos poderiam indicar professores da graduação.

Figura 1. Algumas narrativas de alunos.

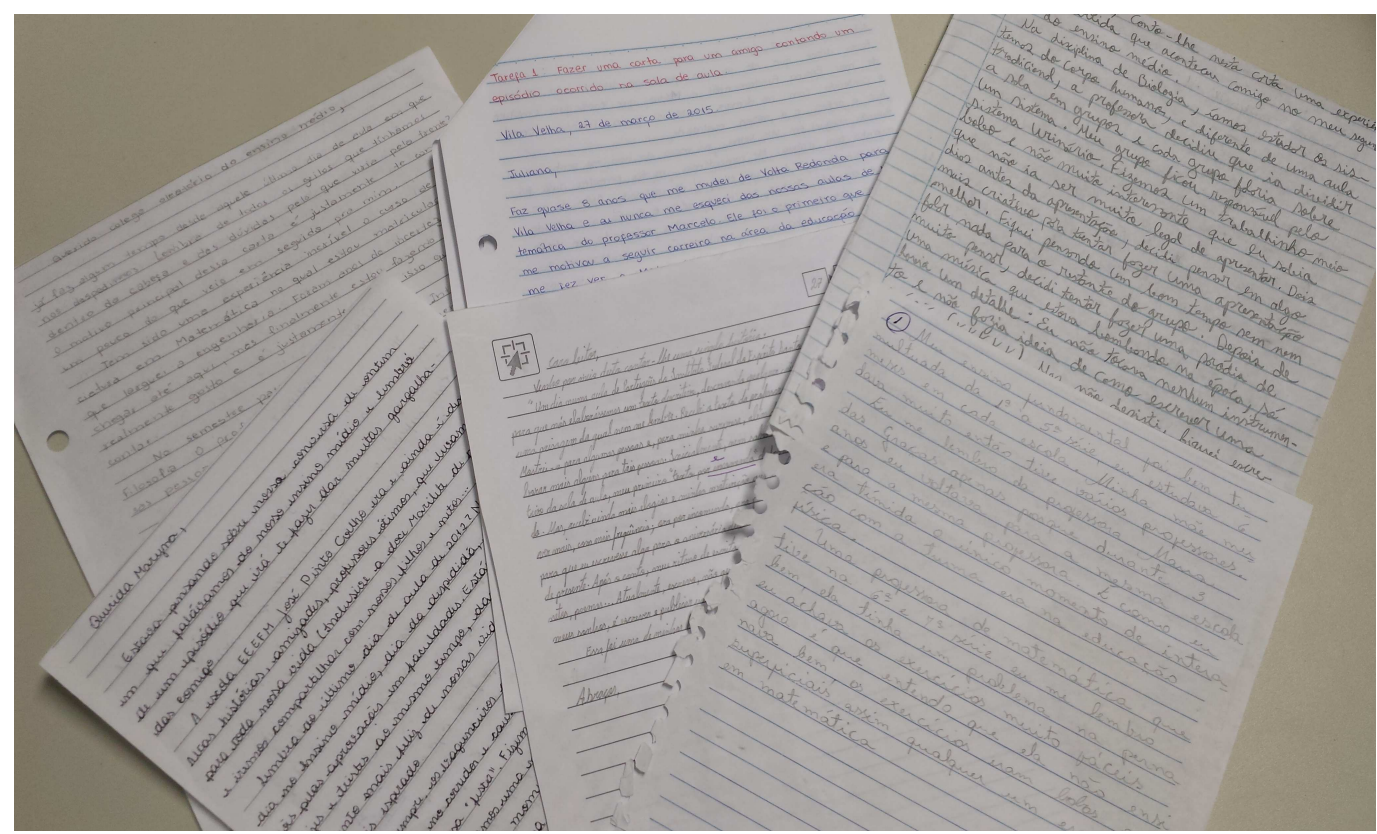

Fonte: dados da pesquisa.

Para participar da pesquisa, os respondentes assinaram um termo de consentimento livre e esclarecido, no qual explicamos os motivos e objetivos da presente pesquisa. Eles foram identificados por um número e pela sua instituição, de maneira a garantir o anonimato atendendo as normas da ética na pesquisa. A instituição corresponde, portanto, ao grupo da coleta de dados. Os números variam de um (1) até o total da amostra em cada caso. Os alunos foram numerados em ordem alfabética. 
Para análise de dados utilizamos a associação, ou seja, analisamos as informações a partir de um modelo teórico prévio, associando o material empírico ao quadro teórico, verificando se há correspondência entre eles (FIORENTINI; LORENZATO, 2006).

Após a coleta, os dados foram analisados a fim de identificar padrões de respostas. Como estratégia, utilizou-se da associação, ou seja, analisamos as informações a partir de um modelo teórico prévio, associando o material empírico ao quadro teórico, verificando se há correspondência entre eles (FIORENTINI; LORENZATO, 2012). Nesse sentido, buscou-se identificar nas narrativas aspectos da formação da identidade docente e os saberes docentes apontados, que é o objetivo do recorte da pesquisa aqui apresentado. 


\section{ANÁLISE DE DADOS}

Apresentamos a seguir a transcrição da narrativa de 4 professores em formação, que entendemos que representam bem o material analisado. De acordo com a ética de pesquisa, seus nomes foram preservados e numeramos em ordem alfabética os alunos de cada instituição. Estamos interessados em analisar as situações vividas e relatadas pelos professores em formação, enquanto eram alunos (ou se viam enquanto alunos), com a intenção de identificar aspectos da formação da identidade docente e os saberes docentes apontados a partir da observação de outros professores.

A maioria das narrativas traz episódios protagonizados por professor e aluno, assim como apontado em outro recorte dessa mesma pesquisa (FRAGA; WROBEL, 2015), e apresenta os saberes docentes que os alunos acham importantes na prática. Para classificar o que foi apresentado pelos alunos, nos baseamos nas dimensões sobre os saberes docentes apontados por Fiorentini (2005): dimensão do saber acadêmico que é aquele trabalhado em diferentes disciplinas do curso de licenciatura, no saber subjetivo do que seja um professoreducador e no saber fazer que está relacionado mais diretamente com a experiência em sala de aula. Essas dimensões foram nossas categorias de análise.

Os professores em formação apontam diferentes dimensões do saber acadêmico. Alguns apontam a dimensão do saber acadêmico quando falam da importância do professor conhecer a matéria que leciona como comentado pela aluna 6 do Ifes (Narrativa 1).

Meu Ensino fundamental foi bem tumultuado da 1a a 5a série. Eu estudava 6 meses em cada escola. Minha mãe mudava muito então tive vários professores.

Eu me lembro da professora M. G. apenas porque durante 3 anos eu voltava para a mesma escola e para a mesma professora. E como eu era tímida o único momento de interação com a turma era na educação física.

Uma professora de matemática que tive na 6a e 7ạ séries eu me lembro bem, ela tinha um problema na perna. Eu achava tudo muito fácil, hoje entendo que ela não ensinava bem, com exercícios bobos e superficiais. Assim qualquer um era bom em matemática. 
Notamos que ao analisar sua posição sobre os exercícios que uma professora passava essa professora em formação já evidencia reflexões sobre o que ela entende atualmente sobre ser um bom professor e o que achava na época. Vemos que a licenciatura já fez modificar sua visão sobre o que é ser um bom professor. Essa futura professora mostra em sua fala que a "professora não ensinava bem", porque abordava coisas superficiais. Entendemos que ela está dando importância para um professor aprofundar os conhecimentos que vai trabalhar, evidenciando a necessidade de saberes acadêmicos, inclusive os matemáticos, para a realização da docência de maneira adequada.

É interessante observar as relações que esses professores em formação fazem ao refletirem sobre os professores que marcaram suas vidas, em especial, perceber como essas reflexões os ajudam no processo formativo. O aluno 1 da UFES narra um professor que foi diferenciado por conseguir relacionar o conteúdo com outras matérias (Narrativa 2). Esse aluno destaca essa questão como uma nova visão do conhecimento matemático, que precisa estar relacionado a outros conteúdos e contextos. Também destaca que mesmo com experiências negativas não desistiu da docência, mas indica a importância de ter um professor experiente na graduação apoiando e acompanhando de perto, de certa maneira destacando o saber acadêmico e da experiência. A partir desse relato percebemos o quanto é importante essa formação acadêmica e, mais ainda, como experiências diferenciadas podem fazer a diferença.

Faz quase 8 anos que me mudei de Volta Redonda para Vila Velha e nunca me esqueci de nossas aulas de matemática do professor M. Ele foi o primeiro que me motivou seguir carreira na área de educação e que me fez ver a matemática com outros olhos.

Me lembro do primeiro dia de aula na 5a série e que em vez de encher o quadro com matéria e vários exercícios de revisão ele propôs desafios e questões de lógica, tudo envolvendo a matemática.

Além de quebrarmos a cabeça para descobrir quais números seriam os próximos da 
sequência que ele passou, também me recordo mais ou menos de um de lógica que perguntava se seria possível colocar um papel entre as folhas 99 e 100 de um livro qualquer.

Nunca paramos para perceber que isso nunca é possível e que tem um motivo para isso. O professor, ao final da aula, desvendou esse e todos os outros mistérios que havia passado. E foi assim que a matemática me fascinou pela primeira vez, que passei a admirar um professor e a querer seguir a mesma carreira que ele.

A partir desse dia, todos os inícios das aulas, ele fazia questão de propor mais um desafio no canto do quadro ou escrever uma piada inteligente envolvendo matemática. Todos eram solucionados ao final da aula.

Posso dizer que ele foi um professor diferenciado. O único em meu ensino fundamental e médio que conseguia envolver o conteúdo com as demais matérias, principalmente informática e artes, e a nossa realidade.

Quando cheguei em Vila Velha no meio do ano, me senti um peixinho fora d'água. Por coincidência, minha primeira aula foi de matemática e tive um choque de realidade. Além do professor, chamado J., ser muito sério e durão, o conteúdo que ele passava eu já tinha estudado em Volta Redonda. Então acho que a combinação de professores totalmente opostos, repetição de conteúdo já visto e o fato das pessoas aqui serem muito fechadas, o que atrapalhou minha aproximação delas, foram decisivos para me tornar uma menina bem tímida, bem diferente do que você costumava me ver. Mas enfim, queria que você soubesse que isso não me fez desistir da carreira, pelo contrário. Atualmente estou fazendo graduação em matemática e vivendo momentos incríveis na Universidade, graças à segunda professora que mais tem me influenciado e me ajudado na minha formação e carreira. Tenho a sorte grande de ter alguém como ela ao meu lado me apoiando e me ensinando coisas incríveis, impossíveis de serem recompensadas.

Nossa, quanto tempo que não nos falamos e nos vemos... Estou à espera de uma carta sua também contando o que tem feito nesses anos todos. Estou curiosa.

Abraços da sua querida amiga.

(Narrativa 2: aluno 1 do Ufes)

Ao lembrar com detalhes desse momento que marcou sua vida e sua escolha profissional 
essa professora em formação evidenciou a maneira como o professor envolvia os alunos destacando o saberfazer. Mas ressalta também que ao apresentar a matemática como desafios ou problemas inteligentes o professor também mostra a importância do conhecimento acadêmico, visto que precisamos conhecer o que ensinamos para podermos apresentá-lo de diferentes maneiras. Quando aponta a forma como o professor age ela também destaca um saber subjetivo, que apresenta no trato com os alunos.

O saber da experiência é destacado poroutros alunos, inclusive em outras disciplinas que não a matemática como é o caso do aluno 3 da UFES, apresentado na sequência (Narrativa 3).

(...) Caro Amigo, conto-Ihe uma experiência divertida que aconteceu comigo no meu segundo ano do ensino médio. Em biologia, íamos estudar os sistemas do corpo humano e, diferente de uma aula tradicional, a professora dividiu a sala em grupos e cada grupo falaria de um sistema. Meu grupo ficou responsável pelo sistema urinário. Fizemos um trabalhinho meio bobo e não muito interessante que eu sabia que não seria legal apresentar. (...) Decidi fazer uma paródia de uma música que estava bombando na época. (...) Ela ficou sensacional, resumia todo o sistema urinário de maneira bem satisfatória e fácil de lembrar. Tínhamos menos de um dia para encontrar alguém que tocasse algum instrumento, Um amigo de outro grupo nos ajudasse com um violão, ensaiamos às pressas e no dia seguinte depois de apresentarmos o que havíamos preparado, distribuímos as letras e cantamos e paródia. Foi um sucesso total, a professora amou, os colegas de sala gostaram e se divertiram bastante e inclusive chamaram outros professores para ouvir a gente cantando.

Depois desse episódio comprei um violão e decidi aprender a tocar. Ainda não toco bem mas já é alguma coisa.

Até hoje lembro da letra que descreve o funcionamento do sistema urinário, sei todos os órgãos envolvidos e a função de cada um e pela intensidade da experiência acredito que nunca mais esquecerei.

Um grande Abraço.

(Narrativa 3: aluno 3 da Ufes) 
É interessante perceber a importância da experimentação, do envolvimento que os alunos precisam ter com o conteúdo, da construção do próprio conhecimento. Quando esse aluno destaca “(...) pela intensidade da experiência acredito que nunca mais esquecerei" vemos que foi algo que o marcou. Esse professor em formação percebe que esses momentos são importantes. O saber-fazer da professora que envolveu os alunos numa ação diferente levouos a viver intensamente essa experiência.

As narrativas trazem ainda o saber subjetivo, quando enfatizam a boa relação professor aluno ou quando relatam conhecimentos adquiridos para além do conteúdo em si, como é o caso do aluno 2 da UFES (Narrativa 4).

(...) Tem sido uma experiência incrível o curso de licenciatura em Matemática no qual estou matriculada desde que larguei a engenharia. Foram anos de incerteza para chegar até aqui, mas finalmente estou fazendo algo que realmente gosto.

No semestre passado fiz a disciplina de Introdução à Filosofia. O professor era fantástico, inteligentíssimo, desses que falam sobre qualquer assunto. Em uma aula ele pediu para escrevermos sobre o mito das cavernas de Platão.

(...) O professor interveio no momento em que a maioria de nós pensávamos que o certo a se fazer é mesmo sair da zona de conforto, e ele disse que não! "não devemos sair da zona de conforto, mas expandi-la e nos manter dentro dela". E isso faz todo o sentido! Ele explicou que sair da zona de conforto é nos expor àquilo que não gostamos, é fazer sacrifícios. Já expandir a própria zona de conforto significa experimentar coisas novas e descobrir aquilo que gostamos mas que bem sabemos ainda, com isso, ampliar nossas possibilidades em todas as áreas da vida. Não há nada errado em se manter dentro da zona de conforto, contanto que nunca deixe de trabalhar para que ela se amplie cada vez mais.

Já imaginou que no meio de tanto cálculo, álgebra e geometria eu poderia aprender esse tipo de lições? Percebi que é importante não ter medo de errar, de desistir, de mudar, de tentar de aprender e isso é muito além de tudo o que pensei que eu fosse aprender na universidade.

Voltando ao nosso tempo de ensino médio e traçando um paralelo? Lembra-se de todos 
os sonhos que tínhamos? Bom, aprendi aqui também que nunca é tarde para mudar em virtude deles. Às vezes a insatisfação naquilo que estamos fazendo pode ser um alerta de que precisamos expandir nossa zona de conforto.

Deixo aqui meu pensamento para que você também reflita sobre e, assim me despeço, sentindo muitas saudades daquele tempo e uma alegria enorme em poder compartilhar isso com você.

Abraço.

(Narrativa 4: aluno 2 da Ufes)

Essa professora em formação destaca que na universidade aprendeu mais do que conhecimentos matemáticos. E que ao relembrar esse professor que a marcou o que vem em destaque é esse conhecimento subjetivo, no qual é necessário dar valor a outros aspectos formativos. É importante saber trabalhar o erro, reconhecê-lo, mas não desistir, conforme destacou. Isso valeu para suas escolhas profissionais, mas também reflete saberes docentes em sala de aula, na medida que todo professor terá que lidar com erros de alunos.

É importante frisar que em uma mesma narrativa, vários saberes aparecem citados. De fato, eles não são isolados e independentes, dissociados. Como em uma engrenagem, um movimenta o outro (Figura 2).

Figura 2. A engrenagem dos saberes docentes.

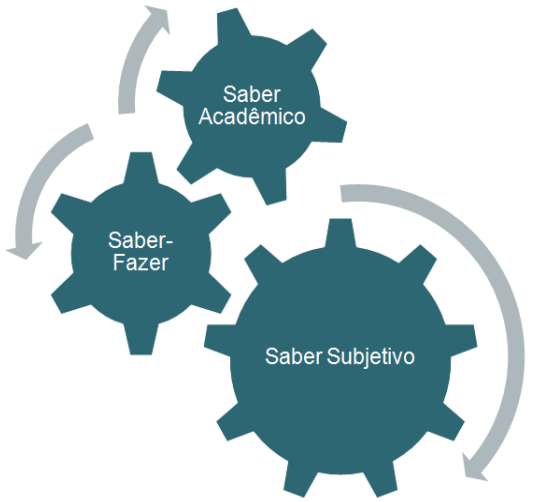

Fonte: dados da pesquisa. 


\section{CONSIDERAÇÕES FINAIS}

As narrativas escritas pelos professores em formação trazem episódios da educação básica e também vividos na universidade. Isso mostra na prática a importância de toda a história acadêmica pregressa do aluno na concepção da sua identidade docente (TARDIFF, 2000).

As histórias apresentadas foram protagonizadas por professor e aluno(s) e apresentam indícios de saberes docentes que os licenciandos acham importantes na prática. Enquanto alunos, os sujeitos conseguem perceber as diferentes dimensões do saber docente.

Tomando como base as dimensões dos saberes docentes apontados por Fiorentini (2005), os licenciandos apontam o conteúdo matemático, mas não se restringem a ele. Isso é positivo, pois é necessário saber o conteúdo a ser ensinado, mas isso não é suficiente para um efetivo processo de ensino e aprendizagem. Destacam que, além disso, é preciso saber ensinar, saber-fazer, observando o aluno, suas dificuldades e buscando maneiras de atingir esses alunos. Mas notamos que os sujeitos privilegiam situações relacionadas ao saber subjetivo do professor, evidenciando posturas do que consideram bons professores, com destaque para relacionamento professor-aluno e capacidade do professor de entender e se colocar no lugar dos alunos. Tivemos diferentes respostas que apontam que ambos os cursos, apesar de diferenças curriculares, estão contribuindo para se pensar o papel do professor de Matemática. Mas cabe ressaltar que não são todos os alunos que relatam as diferentes dimensões e, por isso, defendemos que reflexões dessa natureza devam ser estimuladas no curso de licenciatura em Matemática, em especial quando os alunos já estão realizando estágio supervisionado, visto que é um momento de retorno a escola básica, em uma nova condição. Elas certamente contribuem para que os alunos comecem a se perceber enquanto professores e reconheçam que esta constituição docente é fruto de diferentes experiências vividas antes mesmo da formação inicial.

Precisamos cada vez mais criar situações para se pensar essas dimensões e ampliar a possibilidade de construção de diferentes saberes docentes. Nossos dados reafirmam o que 
Fiorentini (2005) destaca sobre o papel do formador de professores, que precisa ter consciência que diferentes abordagens tanto em disciplinas matemáticas como em disciplinas didáticos pedagógicas contribuem para a construção dos saberes docentes. É necessário criar espaços de aprendizagens e reflexões para que essas dimensões fiquem claras e que os futuros professores compreendam o quanto amplo e complexo é o trabalho docente.

Como proposta futura, gostaríamos de retomar a pesquisa com os alunos que relataram experiências da escola básica, solicitando novos relatos de experiências vividas enquanto alunos, para que possamos verificar a influência (ou não) da graduação nesse olhar dos futuros professores sobre a docência. 


\section{REFERÊNCIAS}

BASTIDES, Ana Carolina. Formação profissional e saberes docentes: um estudo com professores da educação básica. Dissertação (Mestrado em Psicologia Escolar e do Desenvolvimento Humano) - Instituto de Psicologia, Universidade de São Paulo, São Paulo 2012.

CONNELLY, F. M.; CLANDININ, D. J. Relatos de experiencia e investigación narrativa. Em: LARROSA, Jorge et al. Déjame que te cuente: ensayos sobre narrativa y educación. Barcelona: Laertes, 1995. p. 15-59. Disponível em: <app.box.com/s/05kh26sf5ciscgtde4m5>. Acesso em: 26 jul. 2015.

CUNHA, Maria Isabel da. Conta-me Agora! As narrativas como alternativas pedagógicas na pesquisa e no ensino. Rev. Fac. Educ., São Paulo, v. 23, n. 1-2, p. 185-195, jan. 1997. Disponível em: <dx.doi.org/10.1590/S0102-25551997000100010 >. Acesso em: 26 jul. 2015.

FIORENTINI, Dario. A Formação matemática e didático-pedagógica nas disciplinas da Licenciatura em Matemática. Revista de Educação (Campinas), Campinas (SP), v. 1, n.18, p. 107-115, 2005.

NACARATO, Adair Mendes; PAIVA, Maria Auxiliadora V. (Orgs). A Formação do professor que ensina Matemática: avanços e perspectivas. Belo Horizonte: Autêntica, 2006.

NÓVOA, A.; FINGER, M. (org.). O método (auto)biográfico e a formação. Lisboa: Ministério da Saúde/ Departamento de Recursos Humanos da Saúde/ Centro de Formação e Aperfeiçoamento Profissional, 1988.

SHULMAN, L. S. Those who understand knowledge growth. Teaching Educational Researcher, v. 15, n. 2, p4-14, 1986.

- Conocimiento y enseñanza: fundamentos de La nueva reforma. Revista de currículum y formacíon del professorado, 2005, v. 9, n. 2. Disponível em: <ugr.es/local/recfpro/Rev92ART1.pdf>. Acesso em: 31. out 2013.

SILVA, Sandra Aparecida Fraga da; WROBEL, Julia Schaetzle. Saberes necessários aos docentes sob o olhar de professores de matemática em formação. 2015. No Prelo.

TARDIF, Maurice. Lugar e sentido dos conhecimentos universitários na formação dos profissionais do ensino. Em: GARRIDO, Susane Lopes; CUNHA, Maria Isabel da; MARTINI, Jussara Gue. Os rumos da Educação Superior. São Leopoldo: UNISINOS, 2002b. p. 225-246.

ZIBETTI, M. L. T. Do professor que tive ao professor que quero ser - formação inicial de professores e memória educativa. Presença. Revista de Educação, cultura e meio ambiente, ano VII, n. 19 e 20, mar./jun. 2000. 